\title{
Nuclear genes involved in mitochondrial diseases caused by instability of mitochondrial DNA
}

\author{
Joanna Rusecka ${ }^{1}$ - Magdalena Kaliszewska ${ }^{1}$ Ewa Bartnik ${ }^{1,2} \cdot$ Katarzyna Tońska $^{1}$ (]) \\ Received: 7 December 2017 / Accepted: 20 December 2017 / Published online: 17 January 2018 \\ (C) The Author(s) 2018. This article is an open access publication
}

\begin{abstract}
Mitochondrial diseases are defined by a respiratory chain dysfunction and in most of the cases manifest as multisystem disorders with predominant expression in muscles and nerves and may be caused by mutations in mitochondrial (mtDNA) or nuclear (nDNA) genomes. Most of the proteins involved in respiratory chain function are nuclear encoded, although 13 subunits of respiratory chain complexes (together with 2 rRNAs and 22 tRNAs necessary for their translation) encoded by mtDNA are essential for cell function. nDNA encodes not only respiratory chain subunits but also all the proteins responsible for mtDNA maintenance, especially those involved in replication, as well as other proteins necessary for the transcription and copy number control of this multicopy genome. Mutations in these genes can cause secondary instability of the mitochondrial genome in the form of depletion (decreased number of mtDNA molecules in the cell), vast multiple deletions or accumulation of point mutations which in turn leads to mitochondrial diseases inherited in a Mendelian fashion. The list of genes involved in mitochondrial DNA maintenance is long, and still incomplete.
\end{abstract}

Keywords Mitochondrial diseases $\cdot$ Nuclear genes $\cdot$ Mitochondrial DNA instability $\cdot$ Mitochondrial DNA deletions $\cdot$ Depletion

\section{The mitochondrion and its genome}

Mitochondria are cytoplasmic organelles with a double phospholipid membrane and are present in almost all eukaryotic cells. Mitochondria are necessary for cell form and function. Their best recognized role is to generate energy by oxidative phosphorylation, but they also play a key role in synthesis of iron-sulfur centers, fatty acid oxidation, chemical signaling $\left(\mathrm{Ca}^{2+}\right.$ signaling $)$ and programmed cell death. The number of mitochondria in the cell varies and depends on the cell type and energy requirement, where cells with greater energy needs have more mitochondria than cells with smaller needs (Hudson and Chinnery 2006). Mitochondria are considered to be semi-autonomous, because in the course of evolution

Communicated by: Michal Witt

Katarzyna Tońska

kaska@igib.uw.edu.pl

1 Institute of Genetics and Biotechnology, Faculty of Biology, University of Warsaw, Pawinskiego 5a, 02-106 Warsaw, Poland

2 Institute of Biochemistry and Biophysics, Polish Academy of Sciences, Pawinskiego 5a, 02-106 Warsaw, Poland they have maintained their own small genome, known as mitochondrial DNA (mtDNA). The mitochondrial genome was discovered by Nass and Nass in 1963 (Nass and Nass 1963). In the same year, Schatz isolated mtDNA from Saccharomyces cerevisiae (Schatz 1963; Holt and Reyes 2012). mtDNA is required for production of key catalytic subunits of the mitochondrial respiratory chain complexes and therefore is essential for oxidative ATP production. In humans, it is a circular molecule of $16.5 \mathrm{~kb}$ carrying only 37 canonical genes. The mtDNA genes encode: 2 rRNAs, 22 tRNAs and 13 of 83 genes for respiratory chain subunits (MT-ATP6, MT-ATP8, MT-CO1, MT-CO2, MT-CO3, MTCYB, MT-ND1, MT-ND2, MT-ND3, MT-ND4, MT-ND4L, $M T-N D 5, M T-N D 6$ ). Additionally, according to the newest discoveries, human mtDNA also encodes three short peptides, humanin, gau proteins and MOTS-c, with important biological functions, e.g., humanin plays a significant role in protecting neurons from apoptosis in Alzheimer's disease (Shokolenko and Alexeyev 2015; Capt et al. 2016).

All other proteins (over 2000) required for the proper function of all mitochondrial biochemical pathways, including the rest of the subunits of respiratory complexes, are encoded by nuclear genes. This means that mitochondrial DNA expression, maintenance, copy number regulation, and repair 
processes rely on the nuclear genome (Tyynismaa et al. 2005; Capps et al. 2003; DeBalsi et al. 2016; Scheibye-Knudsen et al. 2015).

Several features make mitochondrial DNA unique, for example in mammals it is maternally inherited (Chen et al. 2010). Moreover, there are up to thousands of mtDNA copies in each cell (Suomalainen and Isohanni 2010). When all the mtDNA molecules have the same sequence (wild or mutated) it is called homoplasmy while heteroplasmy implies the mixture of two or more types of mtDNA (for example wild type and mutant). The heteroplasmy level of pathogenic variants correlates with the phenotype to some extent.

\section{Genetics of mitochondrial diseases}

Mitochondrial diseases are defined by a respiratory chain dysfunction and in most of the cases manifest as multisystem and multiorgan disorders with predominant expression in muscles and nerves. Generally, the prevalence of mitochondrial disease is around 1:10,000 and is similar to diseases like phenylketonuria or spinal muscular atrophy but the exact frequencies vary between different populations and are not known for many of them. Prevalence of mitochondrial diseases is different in children $(6.2: 100,000)$ and adult patients $(1: 4300$ affected or at risk) (Lightowlers et al. 2015). Moreover, the prevalence varies between populations of patients, e.g., prevalence of mitochondrial diseases in Spanish adult population (older than 14 years) is 5.7:100,000 (Arpa et al. 2003), in Australia 4.7:100,000 (Skladal et al. 2003).

Gorman et al. (2015) showed that mitochondrial disease is caused by mutations in nuclear genes in 2.9 per 100,000 adults in North East England.

Diseases caused by mtDNA mutations are maternally inherited, while those caused by mutations in nuclear genes encoding proteins more or less directly engaged in the function of the oxidative phosphorylation system (OXPHOS) are inherited in a Mendelian fashion (Wortmann et al. 2015). An interesting subgroup of mitochondrial disorders results from large deletions of mtDNA or its depletion. While single large mtDNA deletions occur spontaneously and are in most cases not transmitted from a mother to her children, multiple mtDNA deletions and depletion have Mendelian inheritance (Wong 2013; Dinwiddie et al. 2013; Lightowlers et al. 2015). The former is the result of the fact that the maintenance of mtDNA relies on proteins encoded in the nuclear genome.

Mitochondrial disorders associated with disturbed mtDNA stability (copy number and quality) are collectively called mitochondrial maintenance diseases or mtDNA depletion syndromes. The main feature of those disorders is rearrangement of the mitochondrial genome seen as multiple deletions of mitochondrial DNA molecules (the presence of multiple classes of mtDNA molecules of different lengths) and/or decrease of mtDNA copy number in cells, known as mtDNA depletion (Krishnan et al. 2008; Nicholls et al. 2014; Wong 2013; Gorman et al. 2015).

\section{Mitochondrial DNA maintenance}

Although mitochondrial DNA is not wound onto histone structures, it does not freely float in mitochondrial matrix. It is covered mainly by TFAM protein discovered as a transcription factor, but mainly engaged in forming the proper shape of the mitochondrial nucleoid and in copy number control (details later). The number of mtDNA molecules in one nucleoid is still being discussed - it seems to be one to a few. Obviously, replication plays the main role in the maintenance of mitochondrial DNA (Campbell et al. 2012).

\section{mtDNA replication machinery}

Initially, the strand displacement model (SDM) of replication was suggested but it was partially incorrect due to artifacts which occurred during the preparation process. An updated version of the SDM is called the RNA intermediate throughout the lagging-strand (RITOLS) model. Both models imply the presence of two origins of replication (ori, $\mathrm{O}$ ), one on the heavy $(\mathrm{H})$ strand and one on the light strand $(\mathrm{L})$, called $\mathrm{OH}$ and OL respectively (Nicholls et al. 2014; Holt and Reyes 2012). OH is located within the non-coding region (NCR) of mtDNA, whereas OL is at two-thirds of the mtDNA length, within a cluster of tRNA genes. Replication starts from $\mathrm{OH}$; polymerase adds nucleotides to an RNA primer and synthesis of the light strand starts only after OL has been reached. The main distinction is that the displaced maternal heavy strand is supposed to be naked in SDM and covered by short RNA fragments in the RITOLS model, but the main assumption, asynchronous replication, is common for both of them (McKinney and Oliveira 2013).

In 2000, Holt and colleagues proposed a new, synchronous model of mitochondrial DNA replication called COSCOFA (conventional strand-coupled Okazaki fragment associated). This model implies that synthesis is initiated bidirectionally from multiple origins of replication at ori zone (ori z). The leading $\mathrm{H}$ strand is synthesized continuously and the lagging L strand is formed without delay as Okazaki fragments (Holt et al. 2000).

It is suspected that different types of mitochondrial replication systems are present in various tissues or depend on the energy state of mitochondria and cells (Martin-Garcia 2013).

The most important enzyme taking part in mtDNA replication is DNA polymerase gamma. Further proteins involved in this process are: Twinkle helicase, single-stranded DNA binding protein (mtSSB; may stabilize the displaced maternal $\mathrm{H}$ 
strand) (Holt and Reyes 2012), topoisomerase (introduces the breakpoint in mtDNA and separates strands), mitochondrial RNA polymerase (mtRNAP; provides RNA primers for initiation of replication), $\mathrm{RNaseH} 1$ and mitochondrial DNA ligase III (Young and Copeland 2016). Defects in the mitochondrial DNA replication process result in a single or multiple mutations in mtDNA and lead to multiple deletions and/or depletion of mtDNA molecules (Hudson et al. 2007).

\section{Genes encoding proteins involved in mitochondrial DNA replication}

The catalytic subunit of DNA polymerase gamma (encoded by the POLG gene) and its processivity factor (encoded by the POLG2 gene) together with Twinkle helicase (encoded by the $T W N K$ gene), DNA replication helicase/nuclease 2 (encoded by the DNA2 gene), single-stranded DNA binding protein 1 (encoded by the $S S B P 1$ gene), primase and polymerase (DNA-Directed) (encoded by the PRIMPOL gene), and mitochondrial genome maintenance exonuclease 1 (encoded by the $M G M E 1$ gene) play the key role in mitochondrial DNA maintenance and replication processes (Fig. 1).

\section{POLG and POLG2 genes}

One of the most important proteins encoded by the nuclear genome involved in replication, expression, maintenance, and repair of mitochondrial DNA is polymerase gamma (Pol $\gamma$ ). Pol $\gamma$ is the only DNA polymerase involved in mtDNA replication present in the human mitochondrion (García-Gómez et al. 2013).

The holoenzyme is composed of a catalytic subunit POLG encoded by the POLG gene (15q26.1, 23,491 bp, 23 exons) and a homodimer of accessory subunits POLG2 encoded by the POLG2 gene (17q23.3, 26,283 bp, 8 exons) (Johnson and Johnson 2001; Oliveira et al. 2015; Hudson and Chinnery 2006).

POLG has a catalytic core with $3^{\prime}-5^{\prime}$ exonuclease activity responsible for proofreading (26-418 amino acids), a linker domain (419-755 amino acids), and 5'-3'polymerase activity responsible for replication (756-1239 amino acids) (Oliveira et al. 2015; Hudson and Chinnery 2006).

The subunit encoded by the POLG gene is necessary for proper function of the enzyme, it enhances enzyme activity by simultaneously accelerating the polymerization rate and suppressing exonuclease activity (Szymanski et al. 2015; Johnson and Johnson 2001; Lee et al. 2009). Polymerase gamma is considered a high fidelity polymerase introducing less than $2 \times 10^{-6}$ errors per nucleotide (Hudson and Chinnery 2006). POLG2 increases the affinity for DNA molecules (DiRe et al. 2009; Szymanski et al. 2015).
Mutations affecting polymerase gamma result in a wide range of genetic syndromes with many mtDNA mutations, deletions, multiple deletions, and depletion of mitochondrial DNA (Linkowska et al. 2015; Hudson and Chinnery 2006). Diseases associated with Pol $\gamma$ dysfunction caused by mutations in the POLG gene include mitochondrial DNA depletion syndrome 4A (Alpers type, MIM 203700), a fatal infant disease with epilepsy and drug induced liver failure, mitochondrial DNA depletion syndrome 4B (MNGIE type, MIM 613662 ) with gastrointestinal involvement, mitochondrial recessive ataxia syndrome (includes SANDO and SCAE, MIM 607459), and relatively benign progressive external ophthalmoplegia autosomal dominant 1 (MIM 157640) and autosomal recessive 1 (MIM 258450) (Naïmi et al. 2006). All the above-mentioned diseases, which differ in severity and range of symptoms, may be caused by the same spectrum of POLG mutations. Progressive external ophthalmoplegia with mitochondrial DNA deletions, autosomal dominant 4 (MIM 610131) develops as a result of mutations in the POLG2 gene.

\section{TWNK}

Polymerase $\gamma$ cooperates with TWINKLE helicase (also known as PEO1) encoded by the $T W N K$ gene (10q24.31, 11,866 bp, 6 exons). TWINKLE is a mitochondrial $5^{\prime}-3^{\prime}$ helicase necessary for replication of human mitochondrial DNA (Milenkovic et al. 2013; Tyynismaa et al. 2004). It binds to and unwinds double-stranded DNA (dsDNA) by breaking hydrogen bonds between annealed nucleotide bases and separating to single strands (Tyynismaa et al. 2005; Korhonen et al. 2003; García-Gómez et al. 2013; Cieskielski et al. 2016; Lamantea et al. 2002).

Mutations in the TWNK gene studied in cell cultures and deletor mice resulted in blocking of the replication process, accumulation of intermediates and finally in multiple mtDNA deletions (Goffart et al. 2009).

Known mutations result in insufficient mitochondrial DNA synthesis and lead to deletions and depletion of mtDNA (Nikkanen et al. 2016; Paramasivam et al. 2016). They are a frequent cause of progressive external ophthalmoplegia with mitochondrial DNA deletions, autosomal dominant 3 (MIM 609286) but in rare cases may lead to recessive diseases like mitochondrial DNA depletion syndrome 7 (hepatocerebral type) (MIM 271245) and Perrault syndrome 5 (MIM 616138),

\section{SSBP1}

Stabilization of the replication fork through preventing binding strands of a replicated fragment of DNA from forming secondary structures and degradation is the main role of single stranded DNA binding protein 1 (SSBP1) encoded by the SSBP1 gene (7q34, 12,180 bp, 9 exons). SSBP1 interacts with polymerase gamma and helicase Twinkle and strengthens 


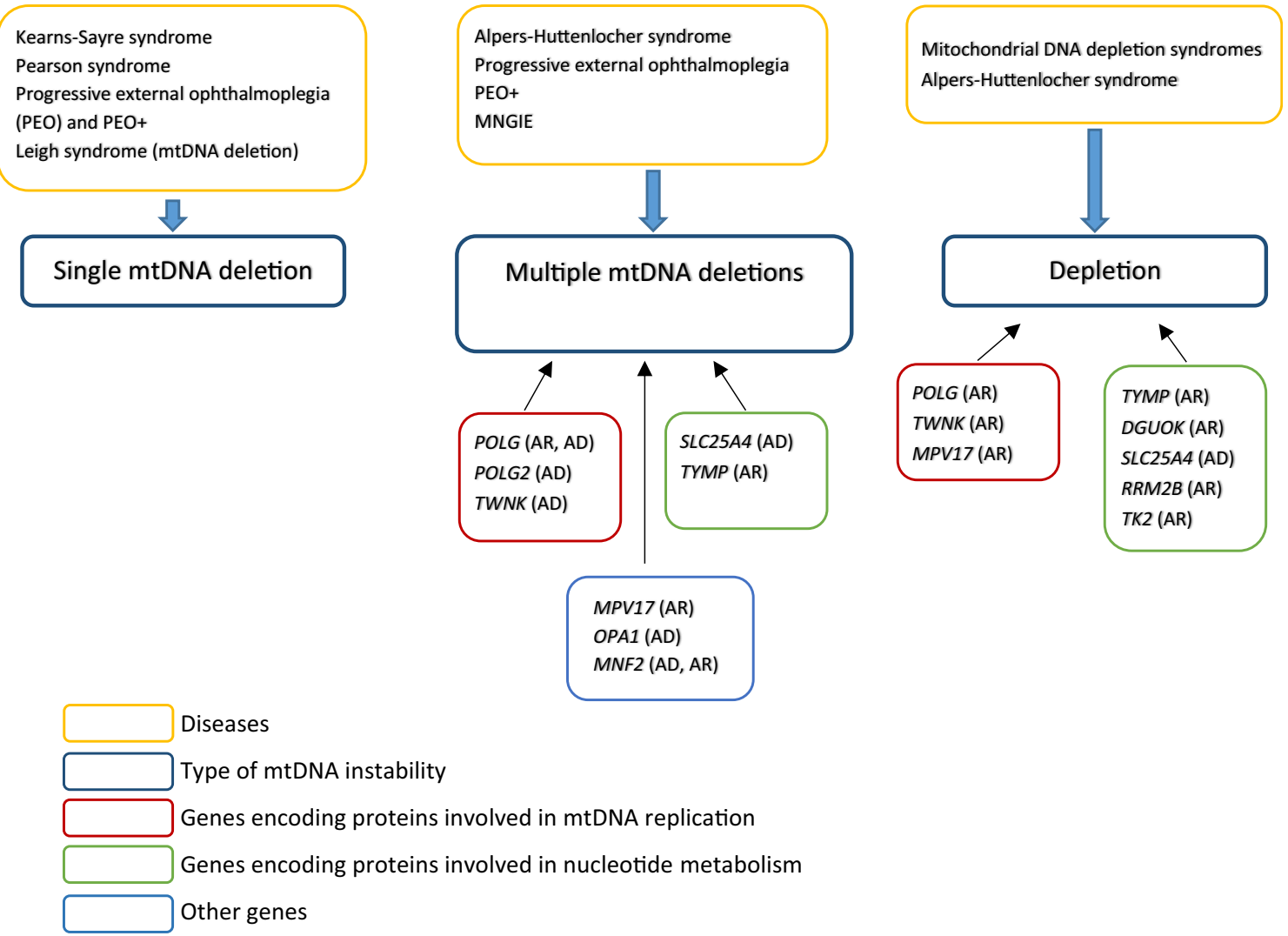

Fig. 1 Mitochondrial DNA instability types with their molecular backgrounds and diseases they cause. AR - autosomal recessive, AD - autosomal dominant

their functions (Hudson and Chinnery 2006; Ruhanen et al. 2010).

Studies on Saccharomyces cerevisiae RIMI null mutants (RIMI encodes ssDNA binding protein) (Van Dyck et al. 1992) and mutants in the lopo (low power) gene from Drosophila melanogaster (which affect the mitochondrial single-stranded DNA-binding protein) (Maier et al. 2001) showed depletion of mitochondrial DNA and confirmed that this protein is necessary for replication and maintenance of mtDNA. In HeLa cell cultures with silenced SSBP1 the mtDNA/nDNA ratio decreased and synthesis of the D-loop was affected (Ruhanen et al. 2010). No pathogenic variants in this gene have been described.

\section{PRIMPOL}

The PRIMPOL gene (4q35.1, 52,347 bp, 16 exons) encodes nuclear and mitochondrial primase and DNA directed polymerase. PRIMPOL plays a key role in mtDNA replication initiation. Moreover, it enables the replication machinery to replicate past DNA lesions (translesion synthesis, TLS), e.g., in apurinic/apyrimidinic sites (AP sites). This protein is present both in the nucleus and mitochondria. Silencing of the PRIMPOL gene in human fibroblasts leads to multiple mtDNA deletions and depletion. A PRIMPOL mouse knockout is viable but mtDNA replication deficiency is observed on the cellular level. This confirms that absence of PRIMPOL has multiple adverse effects on mtDNA synthesis (García-Gómez et al. 2013). Mutations in this gene have been shown to result in autosomal dominant myopia (type 22, MIM 615420).

\section{DNA2}

A member of the DNA2/NAM7 helicase family, DNA2 is a DNA replication helicase/nuclease 2 enzyme encoded by the DNA2 gene (10q21.3, 58,458 bp, 22 exons). It has nuclease, helicase, and ATPase activity and interacts with polymerase gamma by stimulating its catalytic activity. DNA2 removes RNA primers and stabilizes mtDNA structure during the replication process; thus, playing an important role in the maintenance of mitochondrial DNA. Moreover, DNA2 participates in repair of small DNA lesions induced by oxidation, alkylation or spontaneous hydrolysis and is critical for long-patch base-excision repair (LP-BER) (Ronchi et al. 2013).

Mutations in DNA2 are associated with recessive Seckel syndrome 8 (MIM 615807) and dominant progressive external ophthalmoplegia with mitochondrial DNA deletions (MIM 615156). 


\section{MGME1}

The MGME1 gene (20p11.23, 22,529 bp, 8 exons) encodes mitochondrial genome maintenance exonuclease 1 (MGME1) protein probably involved in mtDNA repair (Uhler et al. 2016).

MGME1 removes flaps (last 20-50 nt) during replication and enables the processing of mtDNA ends due to the ability to cleave dsDNA in both $5^{\prime}-3^{\prime}$ and $3^{\prime}-5^{\prime}$ directions. Thus this exonuclease can cut $5^{\prime}$ and $3^{\prime}$ flaps. Moreover, MGME1 may enhance exonuclease activity of polymerase gamma (Nicholls et al. 2014; Uhler et al. 2016).

Studies on human fibroblast culture with null MGME1 show that the absence of MGME1 leads to large mtDNA rearrangements such as deletions and depletion. Significant lengthening of the D-loop leading to incorrect processing of the mtDNA 5'end was observed as well (Nicholls et al. 2014).

$M G M E 1$ loss-of-function mutations lead to mitochondrial disease with DNA depletion, deletions, duplications, and rearrangements and result in mitochondrial DNA depletion syndrome 11 (MIM 615084).

\section{RNASEH1}

Ribonuclease H1, encoded by the RNASEH1 gene (2p25.3, $33,559 \mathrm{bp}, 14$ exons) is an endonuclease involved in DNA replication and repair processes both in the nucleus and mitochondria, but in mitochondria it is the only ribonuclease of that type while in the nucleus there are two (besides ribonuclease H2). Ribonuclease H1 specifically digests doublestranded DNA-RNA hybrids and is necessary to produce primers for mtDNA replication.

It was shown, both in mice and human, that loss of RNaseH1 activity disturbs mtDNA replication. In mice, a knockout of Rnaseh1 leads to embryonic lethality with mtDNA depletion (Cerritelli et al. 2003). In human, mutations in RNASEH1 have been recently attributed to autosomal recessive PEO with mtDNA deletions (MIM 616479) (Reyes et al. 2015).

\section{Genes encoding proteins involved in transcription of mtDNA}

The transcription machinery is not only essential for gene expression but also mtDNA copy number regulation as it is responsible for the synthesis of the primers for replication. Mitochondrial RNA polymerase POLMRT and a set of transcription factors: TFAM, TEFM, and TFB2M are responsible for that process.

The human mitochondrial genome contains two transcription promoters: LSP and heavy-strand promoter 1 (HSP1) and HSP2 (Lodeiro et al. 2012). Initiation of transcription from
HSP promoter is only POLMRT dependent. POLMRT generates short RNA primers near oriL (during the replication process this region becomes single stranded and forms a loop structure). Efficient initiation of transcription from LSP requires cooperative action of POLMRT and transcription factors TFAM and TFB2M (Litonin et al. 2010).

\section{POLRMT}

Mitochondrial RNA polymerase encoded by the POLRMT gene (19p13.3, 23,346 bp, 21 exons) is responsible for transcription of the mitochondrial genome and also provides primers for mtDNA replication, therefore all changes in the enzyme structure (or transcription complex) may impact mtDNA stability. POLRMT together with TFAM, TEFM, and TFB2M forms a transcription complex (Kühl et al. 2016; Posse et al. 2015; Minczuk et al. 2011).

TFB1M and TFB2M interact directly with POLRMT, help in promoter recognition, and increase transcription efficiency 100-200-fold as compared with RNA polymerase alone (Falkenberg et al. 2002; Litonin et al. 2010).

\section{TFAM}

TFAM (10q21, 14,088 bp, 9 exons) is the mitochondrial transcription factor A coding gene also known as TCF $6 L 3$ or $m t T F A$. TFAM is a key activator of mitochondrial transcription, plays an important role in mitochondrial DNA replication and copy number regulation, and is crucial for mitochondrial biogenesis. TFAM expression and turnover depends on the interaction between POLMRT, TFAM, and mitochondrial DNA (Picca and Lezza 2015; Kang et al. 2007; Ekstrand et al. 2004). In vitro experiments show that equimolar amounts of TFAM and mtDNA template result in the maximal transcription level (Litonin et al. 2010). Change in TFAM expression results in change of the protein level and influences mtDNA copy number (it is directly proportional). A mutation in the TFAM gene has been recently described as a cause of neonatal liver failure with mtDNA depletion (Stiles et al. 2016).

\section{TEFM}

The mitochondrial transcription elongation factor encoded by the TEFM gene (17q11.2, $7933 \mathrm{bp}, 4$ exons) is responsible for transcript elongation. TEFM forms a complex with mitochondrial RNA polymerase, interacts with its catalytic domain, enhances processivity (Minczuk et al. 2011), and probably regulates the DNA replication initiation process (Posse et al. 2015). It was shown that when TEFM is absent in a mitochondrial transcription machinery model transcription is terminated and total transcript levels were significantly lower and transcripts were shorter. This indicates that TEFM is essential for full-length mtDNA transcript formation (Posse et al. 2015). 


\section{TFB2M}

Mitochondrial transcription factor B2, also known as mitochondrial $12 \mathrm{~S}$ rRNA dimethylase 2 or mitochondrial dimethyladenosine transferase 2 mtTFB2, encoded by the TFB2M gene (1q44, 25,703 bp, 8 exons) is a part of the mtDNA transcription complex (Moustafa et al. 2015).

Mutations in POLMRT, TEFM, and TFB2M have not been described yet but changes in their expression may cause mitochondrial DNA instability and could lead to mitochondrial disease.

\section{Genes encoding proteins involved in nucleotide metabolism}

Balance in free nucleotide concentrations is very important for proper DNA replication. It is particularly important in mitochondria, because there are no de novo nucleotide biosynthesis pathways. Mitochondria rely mainly on salvage pathways localized partially in mitochondria and partially in the cytoplasm. Imbalance in free nucleotide concentrations leads to disturbances in mtDNA replication and in consequence to mtDNA copy number decrease or to the appearance of multiple deletions.

There are two deoxyribonucleoside kinases expressed in mitochondria phosphorylating purine and pyrimidine deoxyribonucleosides. Thymidine kinase-2 (TK2) phosphorylates deoxythymidine, deoxycytidine, and deoxyuridine, while deoxyribonucleoside kinase (dGK) phosphorylates deoxyguanosine and deoxyadenosine (Saada et al. 2001). The $R R M 2 B$ gene encodes a protein participating in catalytic conversion of ribonucleoside diphosphates (NDP) to deoxyribonucleoside diphosphates (dNDP) - basic elements for DNA synthesis (Pontarin et al. 2012).

\section{TK2}

The TK2 gene (16q21, 42,410 bp, 12 exons) encodes a mitochondrial matrix enzyme - thymidine kinase 2 (TK2). TK2 is an enzyme essential for mtDNA maintenance, catalyzes the rate-determining step of the pyrimidine salvage pathway (Tyynismaa et al. 2012) and generates (by phosphorylation) thymidine monophosphate (TMP), cytidine monophosphate (CMP) and deoxyuridine from deoxypyrimidine nucleosides (Cámara et al. 2015; Saada et al. 2001).

Mutations in the TK2 gene result in a decrease of enzyme activity which impairs recycling of mtDNA nucleotides and finally causes progressive muscle weakness (myopathy) and mitochondrial DNA depletion syndrome 2 (myopathic type, MIM 609560) (Cámara et al. 2015; Saada et al. 2001; Wang et al. 2003).
Approximately 30 pathogenic mutations in the TK2 gene have been described (ClinVar) with a hot spot in exon 5 (Manusco et al. 2003).

For example, Cámara et al. (2015) observed that compound mutations in the TK2 gene (p.T108 M and p.K202del) were present in DNA isolated from muscle biopsies from patients with myopathy. They also observed a dramatic decrease of mtDNA copy number in cells. Structural analysis of the enzyme showed that missense mutations were linked with binding affinities of dTMP and dCTP (Cámara et al. 2015). Mutation p.T108 M was also described by Behin et al. (2012) and Paradas et al. (2013) and was associated with a $30 \%$ depletion of mtDNA and deletion of $45 \%$ of mtDNA molecules when compared to controls.

\section{DGUOK}

Deoxyguanosine kinase (dGK), another matrix enzyme, encoded by the DGUOK gene ( $2 \mathrm{p} 13,32,136 \mathrm{bp}, 8$ exons) provides phosphorylated purines necessary for mtDNA synthesis (Jullig and Eriksson 2000; Ronchi et al. 2012). Mutations in this gene lead to mitochondrial DNA depletion syndrome 3 (hepatocerebral type) (MIM 251880).

In silico analysis suggested that the most frequent mutations in the gene affect the structure of dGK. Biochemical analysis of the activity of dGK isolated from skeletal muscles from myopathic patients showed that mutations may impair the enzyme function (Ronchi et al. 2012).

\section{RRM2B}

$R R M 2 B$ gene (8q22.3, 34,618 bp, 9 exons) encodes ribonucleotide reductase regulatory TP53 inducible subunit M2B (p53R2), a part of ribonucleotide reductase. This cytoplasmic enzyme is responsible for conversion of ribonucleoside diphosphates to deoxyribonucleoside diphosphates and is an element of the de novo nucleotide biosynthesis pathway. Ribonucleotide reductase is composed of large R1 and small $\mathrm{R} 2$ subunits. There are two types of R2 subunits in the cell. One is present during the $\mathrm{S}$ phase of the cell cycle only, the second one, encoded by $R R M 2 B$, provides the basal level of deoxyribonucleoside diphosphates. mtDNA replication, generally independent of cell cycle, takes place not only during the $\mathrm{S}$ phase, p53R2 protein is crucial for mtDNA synthesis.

Mutations in RRM2B lead to mtDNA depletion (Pontarin et al. 2012).

Diseases associated with mutations in the $R R M 2 B$ gene include mitochondrial DNA depletion syndrome $8 \mathrm{~A}$ (encephalomyopathic type with renal tubulopathy) (MIM 612075), mitochondrial DNA depletion syndrome 8B (MNGIE type) (MIM 612075), and progressive external ophthalmoplegia with mitochondrial DNA deletions, autosomal dominant 5 (MIM 613077). 


\section{TYMP}

Thymidine phosphorylase (TP) is another protein important for nucleotide biosynthesis encoded by the TYMP gene (22q13.33, $4334 \mathrm{bp}, 10$ exons). This cytosolic enzyme of the salvage pathway catalyzes the cleavage of thymidine into thymine and 2-deoxy- $\alpha$-D-ribose-1-phosphate and plays an important role in catabolic processes (Javaida et al. 2016). TP is also considered a promoter of tumor growth and metastasis. Overexpression prevents apoptosis and induces angiogenesis and is associated with tumor aggressiveness and poor prognosis (Bronckaers et al. 2009).

Mutations in TYMP lead to accumulation of nucleosides and an imbalance in the mitochondrial nucleotide pool and results in MNGIE type autosomal recessive mitochondrial DNA depletion syndrome 1 (MIM 603041) (Table 1).

\section{SLC25A4}

The SLC25A4 gene (4q35.1, 7144 bp, 4 exons) encoding a heart muscle specific isoform of a solute carrier family 25 (mitochondrial carrier, adenine nucleotide translocator) member 4 also known as ANT1 was the first gene in which mutations responsible for mtDNA instability were described (Kaukonen et al. 2000). The gene product (monomer protein) forms a pore at the mitochondrial inner membrane. ANT1 predominates in post-mitotic tissues such as muscles and heart (Pebay-Peyroula et al. 2003; Ahmed et al. 2015). ANT1 regulates ATP and ADP transport - it transfers ADP from the cytoplasm to the mitochondrial matrix and ATP from the matrix to the cytoplasm (Neckelmann et al. 1987; Kawamata et al. 2011). The exact mechanism of mtDNA destabilization by the SLC25A4 mutations is not known. Definitely, the ADP/ ATP balance is important for maintenance of the membrane potential. It is also postulated that ATP and ADP concentration may influence dATP quantity and also affect proper DNA/RNA hybrid formation during replication.

Most of the described SLC25A4 mutations cause misfolding of the protein and affect intermembrane exchange of molecules leading to inhibition of cell growth. Moreover, the changed ANT1 protein interacts with other membrane proteins and affects their function (Liu et al. 2015).

Mitochondrial DNA instability was shown in SLC25A4 knockout mice (Krishnan et al. 2008).

Mutations in SLC25A4 can be inherited in an autosomal dominant or recessive manner. Dominant mutations leading to progressive external ophthalmoplegia with mitochondrial DNA deletions (PEO) (MIM 609283) seem to show a dominant-negative effect on the molecular level, while the phenotype caused by recessive ones (mitochondrial DNA depletion syndrome 12 (cardiomyopathic type)) (MIM 615418) is more similar to the one obtained for knockout mice.

\section{Genes encoding proteins involved in mitochondrial fusion, fission, and mobility}

Mitochondria are no longer considered as static bean-shaped structures. They move, fuse, and divide and form a network interconnected with the endoplasmic reticulum. Undisturbed fusion, fission, and movement are especially important in neurons, where mitochondria have to travel along axons and dendrites to act in the proper time and place. Fusion and fission are energy dependent so they rely on effective respiration and at the same time quality control of mitochondria is based on fusion and fission. Defects in fusion, as proven in detail in mice, lead to loss of mtDNA copy number, multiple mtDNA deletions, and increase the point mutation rate (Chen et al. 2010). Genes involved in mitochondrial fusion and fission most frequently mentioned in the context of human disease include OPA (OPA1, mitochondrial dynamin like GTPase), MFN1 (mitofusin 1), and MFN2 (mitofusin 2) encoding proteins involved in fusion, FISI (mitochondrial fission 1 protein), DNM1L (dynamin 1-like protein, Drp1), and MFF (mitochondrial fission factor) important for proper mitochondrial division (MacVicar and Langer 2016; Losón et al. 2013).

\section{OPA1}

The OPA1 (3q29, 104,668 bp, 32 exons) gene encodes mitochondrial dynamin like GTPase. OPA1 plays an important role in mtDNA maintenance, mutations in the OPAl gene lead to mtDNA multiple deletions (Hudson et al. 2007). OPA1 protein localizes to the inner mitochondrial membrane where it is involved in cristae formation and proper fusion of the inner membrane. One of the OPA1 isoforms localizes in the nucleoid and seems to be involved in mtDNA replication (YuWai-Man et al. 2010; Elachouri et al. 2011).

More than 200 mutations in the OPA1 gene have been found of both autosomal dominant and autosomal recessive character. They are associated with autosomal dominant optic atrophy 1 (MIM 165500), optic atrophy plus syndrome (MIM 125250) and autosomal recessive Behr syndrome (MIM 210000). In one consanguineous family, mitochondrial DNA depletion syndrome 14 (encephalocardiomyopathic type) (MIM 616896) due to a homozygous OPA1 mutation has been described.

\section{MFN1}

The MFN1 gene (3q26.33, 47,253 bp, 17 exons) encodes a transmembrane GTPase localized in the mitochondrial outer membrane. MNF1 (mitofusin 1) forms homomultimers and heteromultimers with MFN2 (mitofusin 2) and together they are responsible for outer mitochondrial membrane fusion. There are no human diseases attributed to MFN1 mutations. 


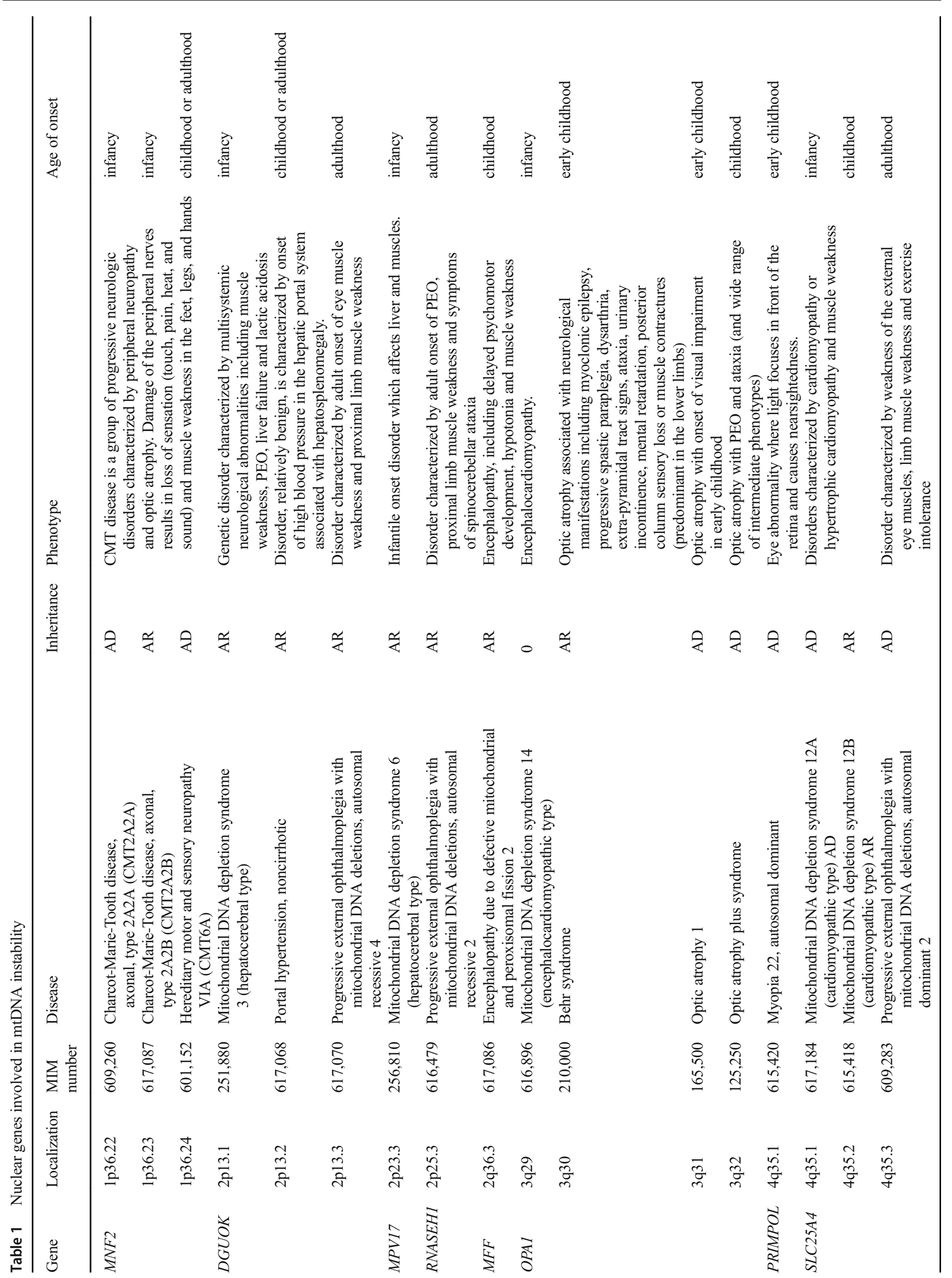



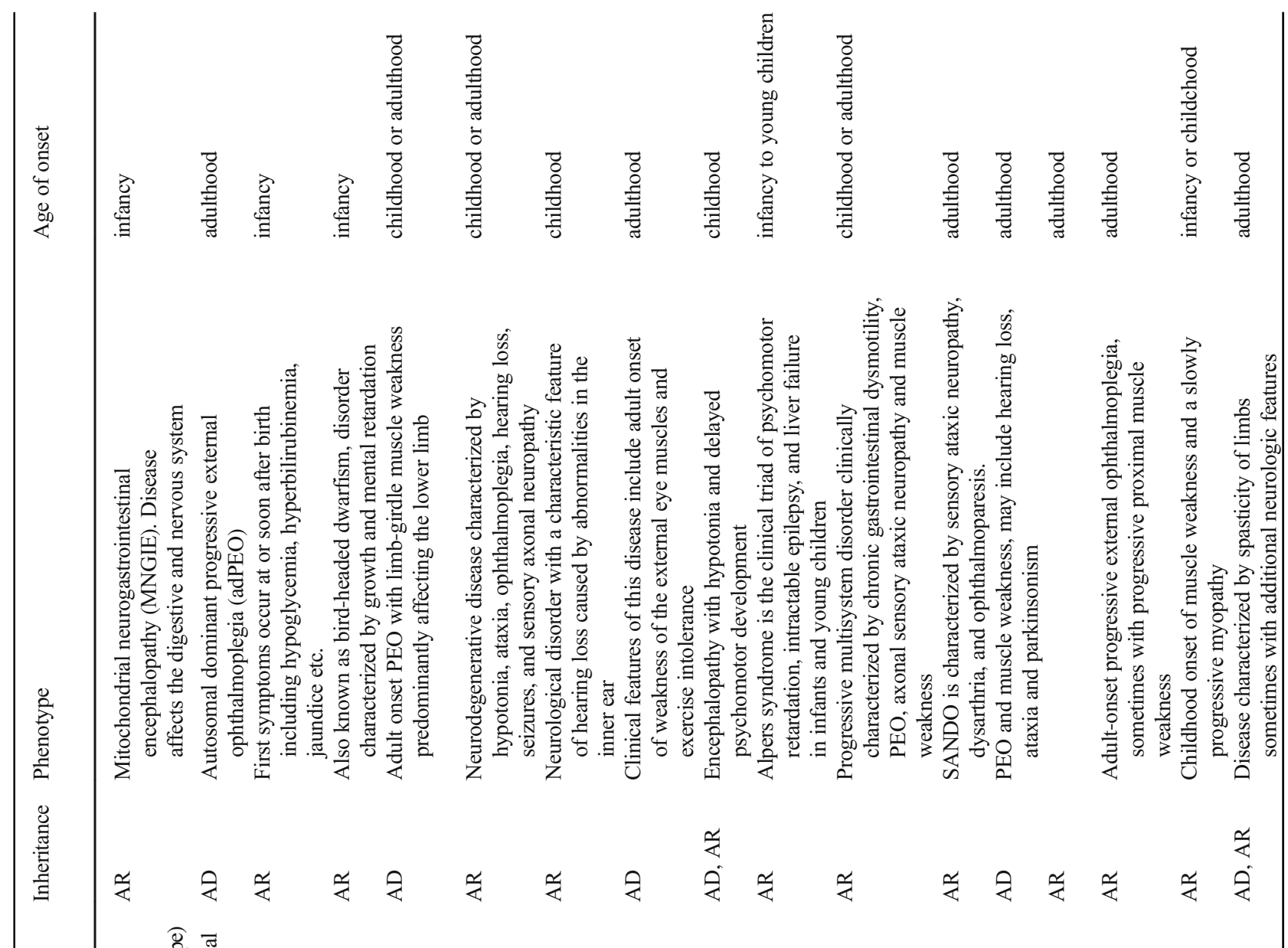

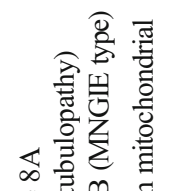

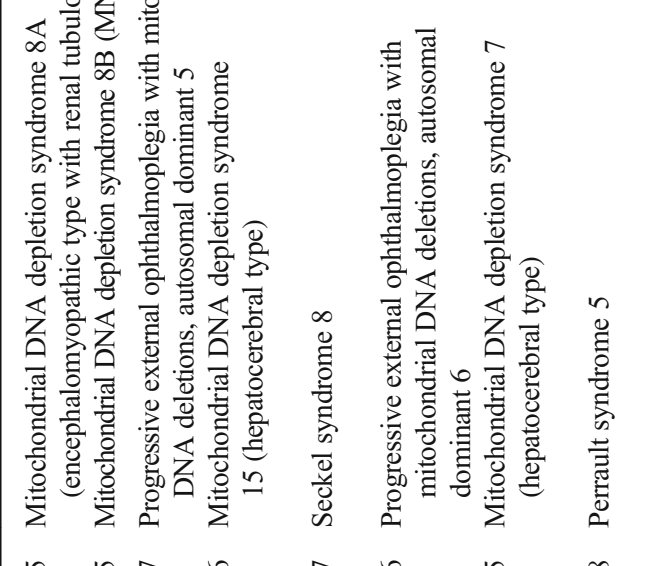

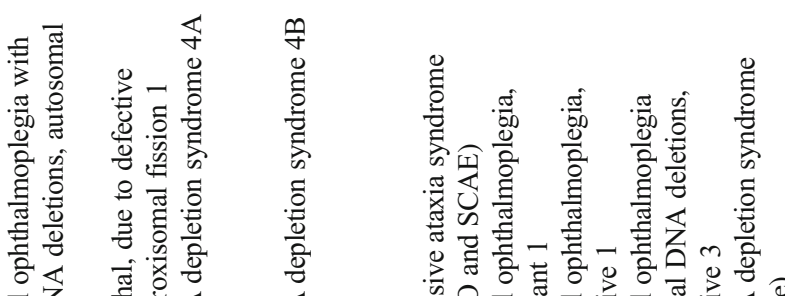

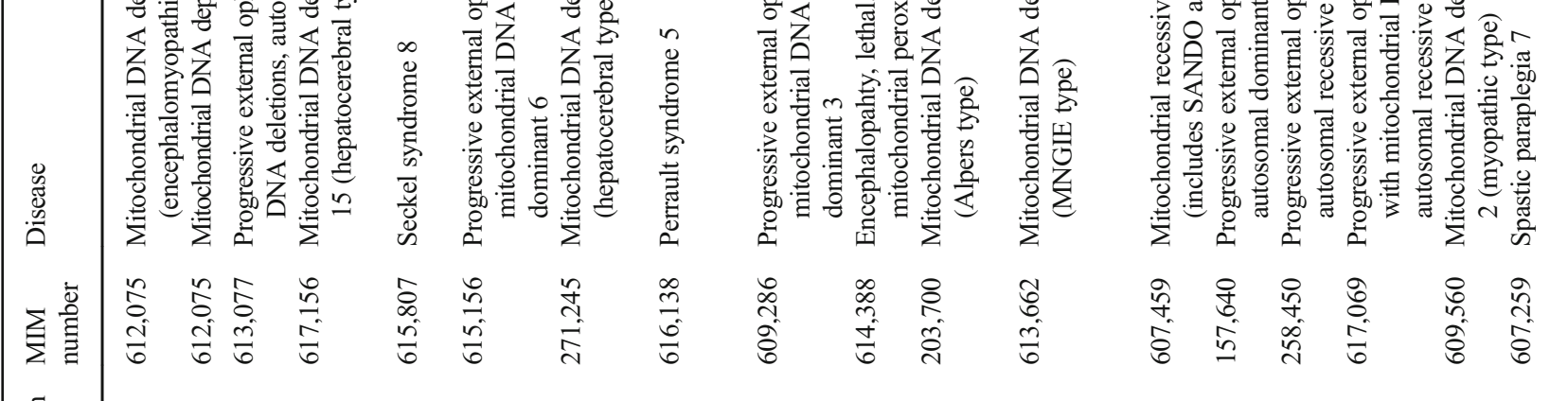

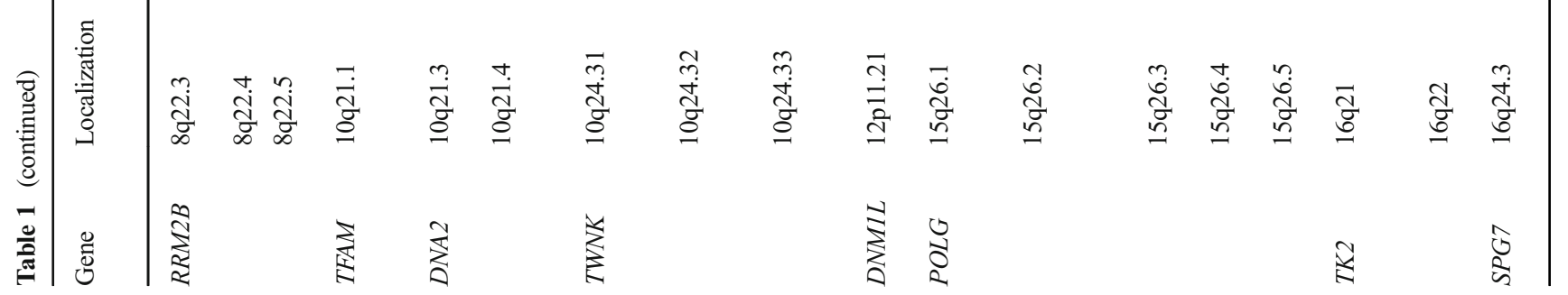


Similar to MFN1, the MFN2 gene (1p36.22, 33,335 bp, 19 exons) encodes a transmembrane GTPase localized in the mitochondrial outer membrane and shares high homology with MFN1. Two transcriptional forms are known. Mitofusin 2 was described as a protein enabling close contact of mitochondria with the endoplasmic reticulum. Recently the opposite was found: depletion of MFN2 results in a closer contact with ER (Filadi et al. 2015).

Mutations in MFN2 are the main cause of autosomal dominant Charcot-Marie-Tooth disease, axonal, type 2A2A (MIM 609260 ) but also autosomal dominant hereditary motor and sensory neuropathy VIA (MIM 601152) and autosomal recessive Charcot-Marie-Tooth disease, axonal, type 2A2B (MIM 617087). mtDNA depletion and multiple deletions were observed in muscles and fibroblasts from patients with $\mathrm{AD}$ Charcot-Marie-Tooth disease caused by MFN2 mutations (Vielhaber et al. 2013).

\section{DNM1L}

The DNMIL (12p11.21, 66,451 bp, 21 exons) encodes another member of the GTPase family: dynamin-1-like protein which regulates mitochondrial function and plays a crucial role in the division, fusion, and fission of mitochondria. DNM1L forms an oligomeric ring at the division spot that narrows and splits the mitochondrial tubule (Fahrner et al. 2016). DNMIL is critically important in human (and general mammalian) development, its absence causes abnormality in embryonic development. Nonsense mutations disturb central nerve system development. Yoon et al. (2016) have shown that if mutations were present in the DNML gene, giant mitochondria with an abnormal shape were present in neurons in human (with compound heterozygous mutations in DNMIL gene) and knock-out mice. Mutations in the DNM1L gene cause encephalopathy which is lethal due to defective mitochondrial and peroxisomal fission (type 1) (MIM 614388, autosomal dominant).

\section{MFF}

The $M F F$ gene encodes the mitochondrial fission factor (2q36.3, 32,686 bp, 13 exons), which is an outer membrane protein required for localization of DNM1L and division of mitochondria. MFF protein together with FIS1 are responsible for recruitment of DNM1L to the division site (Friedman et al. 2011).

Mutations in $M F F$ lead to a similar phenotype to DNM1L mutations (encephalopathy, lethal, due to defective mitochondrial peroxisomal fission 2, autosomal recessive). 
Fig. 2 The main symptoms of the diseases caused by mitochondrial DNA instability

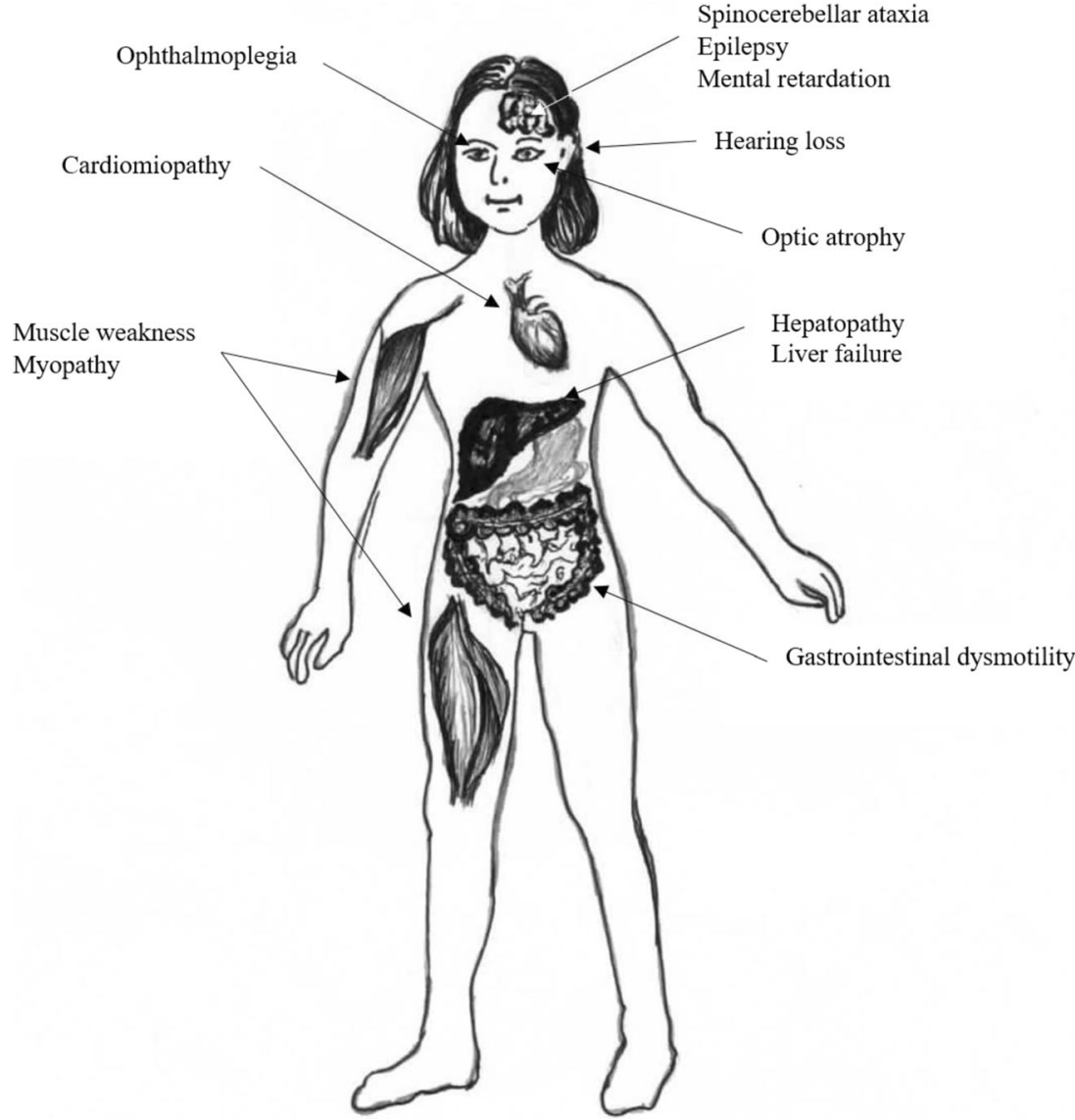

FIS1

FIS1 - tetratricopeptide repeat domain-containing protein 11 encoded by the FIS1 gene (7q22.1, 5479 bp, 5 exons) acts independently of MFF. No diseases caused by FIS1 mutations have been described.

\section{Miscellaneous}

Besides the above-mentioned genes encoding proteins involved in the processes with more or less well described influence on mtDNA stability, there are multiple other genes not involved in any of these processes in which mutations lead to mtDNA deletions or depletion. Here we mention only a few of them with the highest impact on human health.

\section{MPV17}

Although MPV17 (2p23.3, 13,611 bp, 9 exons) mutations were described as a cause of autosomal recessive mitochondrial depletion syndrome ten years ago (Spinazzola et al. 2006), the function of the protein encoded by this gene was not known. Recently (Antonenkov et al. 2015), this inner membrane protein was shown to function as a non-selective channel under a strict control of factors reflecting the energetic state of mitochondria such as membrane potential or redox state.

\section{SPG7}

The SPG7 gene (16q24.3, 66,852 bp, 22 exons) encodes paraplegin which is a component of the mitochondrial AAA protease. Spastic paraplegia 7 takes part in many cellular functions like ribosome assembly regulation, membrane trafficking, protein folding, intracellular motility, organelle biogenesis, and proteolysis. Mutations in SPG7 historically have been attributed to spastic paraplegia 7, autosomal recessive (MIM 607259) but recently were found to be an important factor in mitochondrial diseases (Sánchez-Ferrero et al. 2013; Pfeffer et al. 2014; Gorman et al. 2015). Mutations in that gene lead to chronic progressive external ophthalmoplegia due to disordered mitochondrial DNA maintenance. In the North East England population prevalence of mutations in the SPG7 gene is greater than in TWNK, OPA1, and POLG genes (Pfeffer et al. 2015; Gorman et al. 2015).

As we mentioned at the beginning of this review, mitochondrial diseases are very difficult to diagnose due to complex genotype-phenotype relationships, also called a blended phenotype. This means that mutations in one gene can lead to different clinical phenotypes and mutations in different genes 
can lead to the same signs and symptoms (Wortmann et al. 2015).

\section{Phenotype}

Mitochondrial diseases affect each individual differently. Although mitochondrial disease primarily affects children, adult onset is becoming more common (Fig. 2).

\section{Summary}

Mitochondrial diseases are a heterogeneous group of diseases. Age of onset is very different, from infants to the fifth decade of life. Symptoms involve multiple tissues and most of them may be progressive. Genetic background of this group of diseases in most cases is still unknown. The list of genes involved in mitochondrial DNA maintenance is long and still incomplete.

Although therapeutic options are still limited, effective diagnosis on the clinical and molecular level opens the way to proper treatment. In some cases, targeted therapy is possible such as nucleotide supplementation in the case of patients with TK2 mutations.

Funding This work was supported by National Science Center grant 2014/15/B/NZ5/00434.

\section{Compliance with ethical standards}

Ethical approval This article does not contain any studies with human participants performed by any of the authors.

Conflict of interest The authors declare that they have no conflict of interest.

Open Access This article is distributed under the terms of the Creative Commons Attribution 4.0 International License (http:// creativecommons.org/licenses/by/4.0/), which permits unrestricted use, distribution, and reproduction in any medium, provided you give appropriate credit to the original author(s) and the source, provide a link to the Creative Commons license, and indicate if changes were made.

\section{References}

Ahmed N, Ronchi D, Comi GP (2015) Genes and pathways involved in adult onset disorders featuring muscle mitochondrial DNA instability. Int J Mol Sci 16(8):18054-18076

Antonenkov VD, Isomursu A, Mennerich D, Vapola MH, Weiher H, Kietzmann T, Hiltunen JK (2015) The human mitochondrial DNA depletion syndrome gene MPV17 encodes a non-selective channel that modulates membrane potential. J Biol Chem 290(22):13840 13861
Arpa J, Cruz-Martínez A, Campos Y, Gutiérrez-Molina M, García-Rio F, Pérez-Conde C, Martín MA, Rubio JC, Del Hoyo P, ArpaFernández A, Arenas J (2003) Prevalence and progression of mitochondrial diseases: a study of 50 patients. Muscle Nerve 28(6):690 695

Behin A, Jardel C, Claeys KG, Fagart J, Louha M, Romero NB, Laforet P, Eymard B, Lombes A (2012) Adult cases of mitochondrial DNA depletion due to TK2 defect: an expanding spectrum. Neurology 78: 644-648

Bronckaers A, Gago F, Balzarini J, Liekens S (2009) The dual role of thymidine phosphorylase in cancer development and chemotherapy. Med Res Rev 29(6):903-953

Cámara Y, Carreño-Gago L, Martín MA, Melià MJ, Blázquez A, Delmiro A, Garrabou G, Morén C, Díaz-Manera J, Gallardo E, Bornstein B, López-Gallardo E, Hernández-Lain A, San Millán B, Cancho E, Rodríguez-Vico JS, Martí R, García-Arumí E (2015) Severe TK2 enzyme activity deficiency in patients with mild forms of myopathy. Neurology 84(22):2286-2288

Campbell C, Kolesar J, Kaufman B (2012) Mitochondrial transcription factor a regulates mitochondrial transcription initiation, DNA packaging, and genome copy numer. Biochim Biophys Acta 1819(910):921-929

Capps GJ, Samuels D, Chinnery P (2003) A model of the nuclear control of mitochondrial DNA replication. J Theor Biol 221:565-583

Capt C, Passamonti M, Breton S (2016) The human mitochondrial genome may code for more than 13 proteins. Mitochondrial DNA A DNA Mapp Seq Anal 27(5):3098-3101

Cerritelli $\mathrm{S}$ et al (2003) Failure to produce mitochondrial DNA results in embryonic lethality in Rnaseh1 null mice. Mol Cell 11:807-815

Chen H, Vermulst M, Wang YE, Chomyn A, Prolla TA, McCaffery JM, Chan DC (2010) Mitochondrial fusion is required for mtDNA stability in skeletal muscle and tolerance of mtDNA mutations. Cell 141(2):280-289

Cieskielski G, Rosado-Ruiz F, Kaguni L (2016) Purification and comparative assay of human mitochondrial single-stranded DNA-binding protein. Methods Mol Biol 1351:211-222

DeBalsi K, Hoff K, Copeland W (2016) Role of the mitochondrial DNA replication machinery in mitochondrial DNA mutagenesis, aging and age-related diseases. Ageing Res Rev 33:89-104

Dinwiddie G, Gaskin D, Chan K, Norrington J, McCleary R (2013) Residential segregation, geographic proximity and type of services used: evidence for racial/ethnic disparities in mental health. Soc Sci Med 80:67-75

DiRe M, Sembongi H, He J, Reyes A, Yasukawa T, Martinsson P, Bailey LJ, Goffart S, Boyd-Kirkup JD, Wong TS, Fersht AR, Spelbrink JN, Holt IJ (2009) The accessory subunit of mitochondrial DNA polymerase $\gamma$ determines the DNA content of mitochondrial nucleoids in human cultured cells. Nucleic Acids Res 37(17):5701-5713

Ekstrand MI, Falkenberg M, Rantanen A, Park CB, Gaspari M, Hultenby K, Rustin P, Gustafsson CM, Larsson NG (2004) Mitochondrial transcription factor a regulates mtDNA copy number in mammals. Hum Mol Genet 13(9):935-944

Elachouri G, Vidoni S, Zanna C, Pattyn A, Boukhaddaoui H, Gaget K, Yu-Wai-Man P, Gasparre G, Sarzi E, Delettre C, Olichon A, Loiseau D, Reynier P, Chinnery PF, Rotig A, Carelli V, Hamel CP, Rugolo M, Lenaers G (2011) OPA1 links human mitochondrial genome maintenance to mtDNA replication and distribution. Genome Res 21:12-20

Fahrner JA, Liu R, Perry MS, Klein J, Chan DC (2016) A novel de novo dominant negative mutation in DNM1L impairs mitochondrial fission and presents as childhood epileptic encephalopathy. Am J Med Genet A 170A:2002-2011

Falkenberg M, Gaspari M, Rantanen A, Trifunovic A, Larsson NG, Gustafsson CM (2002) Mitochondrial transcription factors B1 and B2 activate transcription of human mtDNA. Nat Genet 31:289-294 
Filadi R, Greotti E, Turacchio G, Luini A, Pozzan T, Pizzo P (2015) Mitofusin 2 ablation increases endoplasmic reticulummitochondria coupling. Proc Natl Acad Sci U S A 112(17):21742181

Friedman JR, Lackner LL, West M, DiBenedetto JR, Nunnari J, Voeltz GK (2011) ER tubules mark sites of mitochondrial division. Science 334(6054):358-362

García-Gómez S, Reyes A, Martínez-Jiménez MI, Sandra Chocrón E, Mourón S, Terrados G, Powell C, Salido E, Méndez J, Holt IJ, Blanco L (2013) PrimPol, an archaic Primae/polymerase operating in human cells. Mol Cell 52(4):541-553

Goffart S, Cooper HM, Tyynismaa H, Wanrooij S, Suomalainen A, Spelbrink JN (2009) Twinkle mutations associated with autosomal dominant progressive external ophthalmoplegia lead to impaired helicase function and in vivo mtDNA replication stalling. Hum Mol Genet 18(2):328-340

Gorman GS, Schaefer AM, Ng Y, Gomez N, Blakely EL, Alston CL, Feeney C, Horvath R, Yu-Wai-Man P, Chinnery PF, Taylor RW, Turnbull DM, McFarland R (2015) Prevalence of nuclear and mitochondrial DNA mutations related to adult mitochondrial disease. Ann Neurol 77(5):753-759

Holt IJ, Reyes A (2012) Human mitochondrial DNA replication. Cold Spring Harb Perspect Biol 4(12): a012971

Holt I, Lorimer H, Jacobs H (2000) Coupled leading- and lagging-strand synthesis of mammalian mitochondrial DNA. Cell 100(5):515-524

Hudson G, Chinnery P (2006) Mitochondrial DNA polymerase-g and human disease. Hum Mol Genet. 15 Spec No 2:R244-52

Hudson G, Amati-Bonneau P, Blakely EL, Stewart JD, He L, Schaefer AM, Griffiths PG, Ahlqvist K, Suomalainen A, Reynier P, McFarland R, Turnbull DM, Chinnery PF, Taylor RW (2007) Mutation of OPA1 causes dominant optic atrophy with external ophthalmoplegia, ataxia, deafness and multiple mitochondrial DNA deletions: a novel disorder of mtDNA maintenance. Brain 131(2):329-337

Javaida S, Ishtiaqa M, Shaikhb M, Hameeda A, Choudharya MI (2016) Thymidine esters as substrate analogue inhibitors of angiogenic enzyme thymidine phosphorylase in vitro. Bioorg Chem 70:44-56

Johnson A, Johnson KA (2001) Exonuclease proofreading by human mitochondrial DNA polymerase. J Biol Chem 276:38097-38107

Jullig M, Eriksson S (2000) Mitochondrial and submitochondrial localization of human deoxyguanosine kinase. Eur J Biochem 267:54665472

Kang D, Kim S, Hamasaki N (2007) Mitochondrial transcription factor A (TFAM): roles in maintenance of mtDNA and cellular functions. Mitochondrion 7(1-2):39-44

Kaukonen J, Juselius JK, Tiranti V, Kyttälä A, Zeviani M, Comi GP, Keränen S, Peltonen L, Suomalainen A (2000) Role of adenine nucleotide translocator 1 in mtDNA maintenance. Science 289(5480):782-785

Kawamata H, Tiranti V, Magrané J, Chinopoulos C, Manfredi G (2011) adPEO mutations in ANT1 impair ADP-ATP translocation in muscle mitochondria. Hum Mol Genet 20(15):2964-2974

Korhonen JA, Gaspari M, Falkenberg M (2003) TWINKLE has $5^{\prime} \rightarrow 3^{\prime}$ DNA Helicase activity and is specifically stimulated by mitochondrial single-stranded DNA-binding protein. J Biol Chem 278: $48627-48632$

Krishnan KJ, Reeve AK, Samuels DC, Chinnery PF, Blackwood JK, Taylor RW, Wanrooij S, Spelbrink JN, Lightowlers RN, Turnbull DM (2008) What causes mitochondrial DNA deletions in human cells? Nat Genet 40(3):275-279

Kühl I, Miranda M, Posse V, Milenkovic D, Mourier A, Siira SJ, Bonekamp NA, Neumann U, Filipovska A, Polosa PL, Gustafsson CM, Larsson NG (2016) POLRMT regulates the switch between replication primer formation and gene expression of mammalian mtDNA. Sci Adv 2:8
Lamantea E, Tiranti V, Bordoni A, Toscano A, Bono F, Servidei S, Papadimitriou A, Spelbrink H, Silvestri L, Casari G, Comi GP, Zeviani M (2002) Mutations of mitochondrial DNA polymerase $\gamma \mathrm{A}$ are a freuquent cause of autosomal dominant or recessive progressive external ophthalmoplegia. Ann Neurol 52:211-219

Lee YS, Kennedy WD, Yin YW (2009) Structural insights into human mitochondrial DNA replication and disease-related polymerase mutations. Cell 139(2):312-324

Lightowlers R, Taylor R, Turnbull D (2015) Mutations causing mitochondrial disease: what is new and what challenges remain? Science 349: 1494-1499

Linkowska K, Jawień A, Marszałek A, Malyarchuk BA, Tońska K, Bartnik E, Skonieczna K, Grzybowski T (2015) Mitochondrial DNA polymerase $\gamma$ mutations and their implications in mtDNA alterations in colorectal cancer. Ann Hum Genet 79:320-328

Litonin D, Sologub M, Shi Y, Savkina M, Anikin M, Falkenberg M, Gustafsson CM, Temiakov D (2010) Human mitochondrial transcription revisited: only TFAM and TFB2M are required for transcription of the mitochondrial genes in vitro. J Biol Chem 285: 18129-18133

Liu Y, Wang X, Chen XJ (2015) Misfolding of mutant adenine nucleotide translocase in yeast supports a novel mechanism of Ant1-induced muscle diseases. Mol Biol Cell 26(11):1985-1994

Lodeiro M, Uchida A, Bestwick M, Moustafa I, Arnold J, Shadel G, Cameron C (2012) Transcription from the second heavy-strand promoter of human mtDNA is repressed by transcription factor a in vitro. Proc Natl Acad Sci U S A 109(17):6513-6518

Losón OC, Song Z, Chen H, Chan DC (2013) Fis1, Mff, MiD49, and MiD51 mediate Drp1 recruitment in mitochondrial fission. Mol Biol Cell 24(5):659-667

MacVicar T, Langer T (2016) OPA1 processing in cell death and disease the long and short of it. J Cell Sci 129(12):2297-2306

Maier D, Farr C, Poeck B, Alahari A, Vogel M, Fischer S, Kaguni LS, Schneuwly S (2001) Mitochondrial single-stranded DNA-binding protein is required for mitochondrial DNA replication and development in Drosophila Melanogaster. Mol Biol Cell 12:821-830

Manusco M, Filosto M, Bonilla E (2003) Mitochondrial myopathy of childhood associated with mitochondrial DNA depletion and a homozygous mutation (T77M) in the TK2 gene. Arch Neurol 60(7): $1007-1009$

Martin-Garcia J (2013) Mitochondria and their role in cardiovascular disease. In: Introduction to mitochondria in the heart. Springer, Boston, pp 63-65

McKinney E, Oliveira M (2013) Replicating animal mitochondrial DNA. Genet Mol Biol 36(3):308-315

Milenkovic D, Matic S, Kühl I, Ruzzenente B, Freyer C, Jemt E, Park CB, Falkenberg M, Larsson NG (2013) TWINKLE is an essential mitochondrial helicase required for synthesis of nascent D-loop strands and complete mtDNA replication. Hum Mol Genet 22(10): 1983-1993

Minczuk M, He J, Duch AM, Ettema TJ, Chlebowski A, Dzionek K, Nijtmans L, Huynen MA, Holt IJ (2011) TEFM (c17orf42) is necessary for transcription of human mtDNA. Nucleic Acids Res 39(10):4284-4299

Moustafa IM, Uchida A, Wang Y, Yennawar N, Cameron CE (2015) Structural models of mammalian mitochondrial transcription factor B2. Biochim Biophys Acta 1849(8):987-1002

Naïmi M, Bannwarth S, Procaccio V, Pouget J, Desnuelle C, Pellissier JF, Rötig A, Munnich A, Calvas P, Richelme C, Jonveaux P, Castelnovo G, Simon M, Clanet M, Wallace D, Paquis-Flucklinger V (2006) Molecular analysis of ANT1, TWINCLE and POLG in patients with multiple deletions or depletion of mitochondrial DNA by a dHPLCbased assay. Eur J Hum Genet 14(8):917-922

Nass MM, Nass S (1963) Intramitochondrial fibers with DNA characteristics. I. Fixation and electron staining reactions. J Cell Biol 19:593610 
Neckelmann N, Li K, Wade RP, Shuster R, Wallace DC (1987) cDNA sequence of a human skeletal muscle ADP/ATP translocator: lack of a leader peptide, divergence from a fibroblast translocator cDNA, and coevolution with mitochondrial DNA genes. Proc Natl Acad Sci U S A 84(21):7580-7584

Nicholls TJ, Zsurka G, Peeva V, Schöler S, Szczesny RJ, Cysewski D, Reyes A, Kornblum C, Sciacco M, Moggio M, Dziembowski A, Kunz WS, Minczuk M (2014) Linear mtDNA fragments and unusual mtDNA rearrangements associated with pathological deficiency of MGME1 exonuclease. Hum Mol Genet 23(23):6147-6162

Nikkanen J, Forsström S, Euro L, Paetau I, Kohnz RA, Wang L, Chilov D, Viinamäki J, Roivainen A, Marjamäki P, Liljenbäck H, Ahola S, Buzkova J, Terzioglu M, Khan NA, Pirnes-Karhu S, Paetau A, Lönnqvist T, Sajantila A, Isohanni P, Tyynismaa H, Nomura DK, Battersby BJ, Velagapudi V, Carroll CJ, Suomalainen A (2016) Mitochondrial DNA replication defects disturb cellular dNTP pools and remodel one-carbon metabolism. Cell Metab 23:635-648

Oliveira M, Haukka J, Kaguni L (2015) Evolution of the Metazoan Mitochondrial Replicase. Genome Biol Evol 7(4):943-959

Paradas C, Gutierrez Rios P, Rivas E, Carbonell P, Hirano M, DiMauro S (2013) TK2 mutation presenting as indolent myopathy. Neurology 80:504-506

Paramasivam A, Meena A, Pedaparthi L, Jyothi V, Uppin MS, Jabeen SA, Sundaram C, Thangaraj K (2016) Novel mutation in TWNK associated with multiple mtDNA deletions, chronic progressive external ophthalmoplegia and premature aging. Mitochondrion 26:8185

Pebay-Peyroula E, Dahout-Gonzalez C, Kahn R, Trézéguet V, Lauquin G, Brandolin G (2003) Structure of mitochondrial ADP/ATP carrier in complex with carboxyatractyloside. Nature 426:39-44

Pfeffer G, Gorman GS, Griffin H, Kurzawa-Akanbi M, Blakely EL, Wilson I, Sitarz K, Moore D, Murphy JL, Alston CL, Pyle A, Coxhead J, Payne B, Gorrie GH, Longman C, Hadjivassiliou M, McConville J, Dick D, Imam I, Hilton D, Norwood F, Baker MR, Jaiser SR, Yu-Wai-Man P, Farrell M, McCarthy A, Lynch T, McFarland R, Schaefer AM, Turnbull DM, Horvath R, Taylor RW, Chinnery PF (2014) Mutations in the SPG7 gene cause chronic progressive external ophthalmoplegia through disordered mitochondrial DNA maintenance. Brain 137(Pt 5):1323-1336

Pfeffer G, Pyle A, Griffin H, Miller J, Wilson V, Turnbull L, Fawcett K, Sims D, Eglon G, Hadjivassiliou M, Horvath R, Németh A, Chinnery PF (2015) SPG7 mutations are a common cause of undiagnosed ataxia. Neurology 84(11):1174-1176

Picca A, Lezza A (2015) Regulation of mitochondrial biogenesis through TFAM-mitochondrial DNA interactions: useful insights from aging and calorie restriction studies. Mitochondrion 25:67-75

Pontarin G, Ferraro P, Bee L, Reichard P, Bianchi V (2012) Mammalian ribonucleotide reductase subunit $\mathrm{p} 53 \mathrm{R} 2$ is required for mitochondrial DNA replication and DNA repair in quiescent cells. Proc Natl Acad Sci U S A 109(33):13302-13307

Posse V, Shahzad S, Falkenberg M, Hällberg M, Gustafsson CM (2015) TEFM is a potent stimulator of mitochondrial transcription elongation in vitro. Nucleic Acids Res 43(5):2615-2624

Reyes A, Melchionda L, Nasca A, Carrara F, Lamantea E, Zanolini A, Lamperti C, Fang M, Zhang J, Ronchi D, Bonato S, Fagiolari G, Moggio M, Ghezzi D, Zeviani M (2015) RNASEH1 mutations impair mtDNA replication and cause adult-onset mitochondrial encephalomyopathy. Am J Hum Genet 97:186-193

Ronchi D, Garone C, Bordoni A, Gutierrezrios P, Calvo SE, Ripolone M, Ranieri M, Rizzuti M, Villa L, Magri F, Corti S, Bresolin N, Mootha VK, Moggio M, DiMauro S, Comi GP, Sciacco M (2012) Nextgeneration sequencing reveals DGUOK mutations in adult patients with mitochondrial DNA multiple deletions. Brain 135:3404-3415

Ronchi D, Di Fonzo A, Lin W, Bordoni A, Liu C, Fassone E, Pagliarani S, Rizzuti M, Zheng L, Filosto M, Ferrò MT, Ranieri M, Magri F, Peverelli L, Li H, Yuan YC, Corti S, Sciacco M, Moggio M,
Bresolin N, Shen B, Comi GP (2013) Mutations in DNA2 link progressive Myopathy to mitochondrial DNA instability. Am J Hum Genet 92(2):293-300

Ruhanen H, Borriea S, Szabadkaibe G, Tyynismaaa H, Jones A, Kangc D, Taanmande JW, Yasukawa T (2010) Mitochondrial singlestranded DNA binding protein is required for maintenance of mitochondrial DNA and 7S DNA but is not required for mitochondrial nucleoid organization. Biochim Biophys Acta (BBA) Mol Cell Res Vol 1803(8):931-939

Saada A, Shaag A, Mandel H, Nevo Y, Eriksson S, Elpeleg O (2001) Mutant mitochondrial thymidine kinase in mitochondrial DNA depletion myopathy. Nat Genet 29:342-344

Sánchez-Ferrero E, Coto E, Beetz C, Gámez J, Corao AI, Díaz M, Esteban J, del Castillo E, Moris G, Infante J, Menéndez M, Pascual-Pascual SI, López de Munaín A, Garcia-Barcina MJ, Alvarez V (2013) SPG7 mutational screening in spastic paraplegia patients supports a dominant effect for some mutations and a pathogenic role for p.A510V. Clin Genet 83:257-262

Schatz G (1963) The isolation of possible mitochondrial precursor structures from aerobically grown baker's yeast. Biochem Biophys Res Commun 12:448-451

Scheibye-Knudsen M, Fang EF, Croteau DL, Wilson DM, Bohr VA (2015) Protecting the mitochondrial powerhouse. Trends Cell Biol 25(3):158-170

Shokolenko I, Alexeyev M (2015) Mitochondrial DNA: a disposable genome? Biochim Biophys Acta (BBA) Mol Basis Dis 1852: 1805-1809

Skladal D, Halliday J, Thorburn DR (2003) Minimum birth prevalence of mitochondrial respiratory chain disorders in children. Brain 126: 1905-1912

Spinazzola A, Viscomi C, Fernandez-Vizarra E, Carrara F, D'Adamo P, Calvo S, Marsano RM, Donnini C, Weiher H, Strisciuglio P, Parini R, Sarzi E, Chan A, DiMauro S, Rötig A, Gasparini P, Ferrero I, Mootha VK, Tiranti V, Zeviani M (2006) MPV17 encodes an inner mitochondrial membrane protein and is mutated in infantile hepatic mitochondrial DNA depletion. Nat Genet 38:570-575

Stiles AR, Simon MT, Stover A, Eftekharian S, Khanlou N, Wang HL, Magaki S, Lee H, Partynski K, Dorrani N, Chang R, MartinezAgosto JA, Abdenur JE (2016) Mutations in TFAM, encoding mitochondrial transcription factor a, cause neonatal liver failure associated with mtDNA depletion. Mol Genet Metab 119:91-99

Suomalainen A, Isohanni P (2010) Mitochondrial DNA depletion syndromes - many genes, common mechanisms. Neuromuscul Disord 20:429-437

Szymanski MR, Kuznetsov VB, Shumate C, Meng Q, Lee YS, Patel G, Patel S, Yin YW (2015) Structural basis for processivity and antiviral drug toxicity in human mitochondrial DNA replicase. EMBO 34(14):1959-1970

Tyynismaa H, Sembongi H, Bokori-Brown M, Granycome C, Ashley N, Poulton J, Jalanko A, Spelbrink JN, Holt IJ, Suomalainen A (2004) Twinkle helicase is essential for mtDNA maintenance and regulates mtDNA copy number. Hum Mol Genet 13(24):3219-3227

Tyynismaa H, Peltola K, Wanrooij S, Lappalainen I (2005) Mutant mitochondrial helicase Twinkle causes multiple mtDNA deletions and a late-onset mitochondrial disease in mice. Proc Natl Acad Sci U S A 102(49):17687-17692

Tyynismaa H, Sun R, Ahola-Erkkilä S, Almusa H, Pöyhönen R, Korpela M, Honkaniemi J, Isohanni P, Paetau A, Suomalainen L (2012) Thymidine kinase 2 mutations in autosomal recessive progressive external ophthalmoplegia with multiple mitochondrial DNA deletions. Hum Mol Genet 21(1):66-75

Uhler JP, Thörn C, Nicholls TJ, Matic S, Milenkovic D, Gustafsson CM, Falkenberg M (2016) MGME1 processes flaps into ligatable nicks in concert with DNA polymerase $\gamma$ during $\mathrm{mtDNA}$ replication. Nucleic Acids Res 44(12):5861-5871 
Van Dyck E, Foury F, Stillman B, Brill SJ (1992) Single-stranded DNA binding protein required for mitochondrial DNA replication in $\mathrm{S}$. cerevisiae is homologous to E. coli SSB. EMBO 11:3421-3430

Vielhaber S, Debska-Vielhaber G, Peeva V, Schoeler S, Kudin AP, Minin I, Schreiber S, Dengler R, Kollewe K, Zuschratter W, Kornblum C, Zsurka G, Kunz WS (2013) Mitofusin 2 mutations affect mitochondrial function by mitochondrial DNA depletion. Acta Neuropathol 125(2):245-256

Wang L, Saada A, Eriksson S (2003) Kinetic properties of mutant human thymidine kinase 2 suggest a mechanism for mitochondrial DNA depletion myopathy. J Biol Chem 278:6963-6968

Wong LJ (2013) Next generation molecular diagnosis of mitochondrial disorders. Mitochondrion 13:379-387

Wortmann SB, Koolen DA, Smeitink JA, van den Heuvel L, Rodenburg RJ (2015) Whole exome sequencing of suspected mitochondrial patients in clinical practice. J Inherit Metab Dis 38(3):437-443
Yoon G, Malam Z, Paton T, Marshall CR, Hyatt E, Ivakine Z, Scherer SW, Lee KS, Hawkins C, Cohn RD (2016) Lethal disorder of mitochondrial fission caused by mutations in DNMIL. J Pediatr 171: 313-316

Young M, Copeland W (2016) Human mitochondrial DNA replication machinery and disease. Curr Opin Genet Dev 3:52-62

Yu-Wai-Man P, Griffiths PG, Gorman GS, Lourenco CM, Wright AF, Auer-Grumbach M, Toscano A, Musumeci O, Valentino ML, Caporali L, Lamperti C, Tallaksen CM, Duffey P, Miller J, Whittaker RG, Baker MR, Jackson MJ, Clarke MP, Dhillon B, Czermin B, Stewart JD, Hudson G, Reynier P, Bonneau D, Marques W Jr, Lenaers G, McFarland R, Taylor RW, Turnbull DM, Votruba M, Zeviani M, Carelli V, Bindoff LA, Horvath R, Amati-Bonneau P, Chinnery PF (2010) Multi-system neurological disease is common in patients with OPA1 mutations. Brain 133(Pt 3):771-786 